\title{
A Novel Safety Evaluation Method for Mountain Tunnel Surrounding Rock Based on Vague Set
}

\author{
Xiaoguo Chen ${ }^{1}$, Yue Yang ${ }^{2,3 *}$, Xiuhong $\mathrm{Xiao}^{1}, \mathrm{Xin}_{\mathrm{Xu}}{ }^{2,3}$ and Lubo Yang ${ }^{4}$ \\ ${ }^{I}$ School of Information Engineering, Sanming University, Sanming 365004, China \\ ${ }^{2}$ School of Architecture and Civil Engineering, Sanming University, Sanming 365004, China \\ ${ }^{3}$ Key Laboratory of Engineering Material and Structure Reinforement (Sanming University), Sanming 365004, China \\ ${ }^{4}$ Auburn University, Auburn, 36849, USA
}

Received 21 July 2021; Accepted 13 September 2021

\begin{abstract}
The stability of tunnel surrounding rock is the key point of tunnel construction control. Because numerous monitoring indicators are ambiguous and uncertain, it is difficult for traditional safety evaluation methods to predict accurately. To improve the reliability of the safety evaluation results of the tunnel surrounding rock, a safety evaluation method of the surrounding rock in the mountain tunnel was proposed based on the vague similarity theory. First, the new similarity functions were constructed by analyzing the deficiencies of the existing similarity functions, and the function reasonableness and superiority of the new similarity were shown by comparing calculation examples with existing similarity functions. Second, the safety evaluation index system of mountain tunnel surrounding rock was constructed, and the improved new similarity function was used to propose the safety evaluation method based on vague set. Lastly, an extractable safety assessment model was established based on the vague set. The measured data were processed as dimensionless and converted into vague values. Case analysis was conducted according to an engineering project, and the results were consistent with the actual monitored data. Results show as follows: (1) In this paper, the principal and objective weights are obtained by using the analytic hierarchy process (AHP) and entropy weight. The interval weights are constructed and optimized according to the principle of maximizing the distance between the degree of membership and the degree of non-membership. The influence of human factors is avoided effectively. (2) The indicators are processed with the vague values in the model, and the information is comprehensive. The obtained evaluation results are consistent with the actual safety conditions of mountain tunnel construction. The obtained conclusions indicate that the safety evaluation method proposed in this paper can solve the risk evaluation of surrounding rock in mountain tunnels with uncertain characteristics, which can provide a preferred decision reference for design and construction of the tunnel.
\end{abstract}

Keywords: Surrounding rock classification; Similarity function; Interval weight; Vague set theory

\section{Introduction}

Mountain tunnel engineering is a high-risk construction project. Geological and engineering problems such as landslides, large deformations of surrounding rocks, ground subsidence, and water inrush from piping often occur, and the safety situation is outstanding [1]. Especially with the tunnel project presenting a development trend of "deep, long, and large", its quantities and costs are huge. Once an accident occurs, it will not only cause structural damage to the tunnel itself and loss of life and property, but may also cause various incalculable secondary disasters [2]. Therefore, ensuring the safety and stability of tunnel engineering in the design, construction, and operation stages is important. The deformation and stability evaluation and risk analysis of the tunnel engineering surrounding rock will become the key issues that needed to be solved in the safe construction and reliable operation of tunnels.

The stability and risk assessment of tunnel surrounding rock is a complex and non-deterministic problem with a large amount of stochastic, ambiguity, and uncertainty during the analysis. The rock mass is formed by long-term geological evolution, and the spatial distribution of mineral

*E-mail address: 2321120911@qq.com

ISSN: 1791-2377 @ 2021 School of Science, IHU. All rights reserved. doi:10.25103/jestr.144.15 composition and structural characteristics is different. A large amount of uncertainty causes difficulties for the calculation, analysis, and parameter determination of underground rock mass engineering. Traditional deterministic analysis methods can no longer fulfill the actual needs of engineering. The safety evaluation methods of tunnel surrounding rock mostly use the elastic wave velocity method, artificial neural network, grey theory, fuzzy mathematics, extension theory, set pair analysis theory, and so on [3-9]. These studies have achieved certain results, but they also have their own shortcomings. Among them, elastic wave velocity method and gray theory mostly used real numbers to express identified evaluation information, and it is impossible to process uncertain evaluation information. Although extension theory and set pair analysis theory can deal with dynamic uncertain problems to a certain extent, they still fail to solve the fuzzy expression of evaluation information. Fuzzy comprehensive evaluation method can only describe the degree of certainty in the uncertain evaluation information, and cannot describe the degree of hesitation in the information. That is, the uncertain evaluation information is not described accurately. To solve such problems, the hierarchical analysis method and entropy method are adopted to construct the index interval weights based on the vague set theory. The weights are optimized according to the principle of maximizing the absolute value 
of the difference between the degree of membership and the degree of non-membership to avoid the influence of human factors. The safety risk assessment method of surrounding rock of mountain tunnels is established by using the improved new similarity function, which provides a theoretical reference for tunnel safety assessment.

\section{State of the art}

With the rapid development of China's transportation industry, the number of highway tunnels and the scale of construction have increased year by year. Ensuring safe construction is of vital importance. Tunnel engineering is mostly in the complex and changeable rock mass, which is susceptible to the geological environment and rock attributes, making it difficult to divide its surrounding rock level accurately. As a result, it needs to change the design in the construction process often, which will not only delay the progress of the project, but also cause the loss of personnel and property [10]. To ensure the smooth progress of the highway tunnel construction, the establishment of a fast, practical, and effective tunnel surrounding rock grading method is an urgent problem for the builders to solve. At present, there are numerous methods for the highway tunnel surrounding rock classification, among which Lu Yuming [11] applied the cloud model theory to the comprehensive classification of the tunnel surrounding rock. Zhang Fengrui et al. [12] graded the tunnel surrounding rock, and the results are consistent with the engineering exploration grade. Napoli et al. [13] proposed a highway tunnel surrounding rock grading method based on set-pair analysis of connection numbers. Atzl et al. [14] used the extension theory to grade the tunnel surrounding rock. The index values were all real numbers and the weight difference was insignificant. In engineering practice, the core problem of the difference of complex tunnel surrounding rock is that its different effect on engineering safety. The difficulty, way, and effects of tunnel safety control are also different. Therefore, it is necessary to evaluate its safety.

In terms of the surrounding rock safety evaluation method of mountain tunnels, Flora et al. [15] selected the uniaxial saturated compressive strength of the rock, rock quality index, rock mass integrity coefficient, the structural plane strength coefficient, the groundwater interaction index, the angle between the hole axis, and the main structural plane as the evaluation index. The expert evaluation method was used to determine the weight coefficient of each index, and the risk warning model was established. Analysis results have shown that the efficiency coefficient method had certain engineering application value. Erharter et al. [16] selected six indicators, including rock softening coefficient, groundwater flow, rock integrity index, rock uniaxial compressive strength, structural surface status, and the angle between the main structural surface and the tunnel axis to establish a safety risk assessment system for the surrounding rock of the water-rich tunnel. The link membership function was constructed by using the principle of set-pair analysis, the index weight was calculated with the analytic hierarchy process (AHP) method, and the tunnel surrounding rock risk level was obtained according to the principle of maximum membership. Kang et al. [17] established a radar chart method evaluation model combining numerical values and graphics for the risk assessment of karst tunnels under complex geological conditions, introduced four reference samples corresponding to the risk grade, and the comprehensive evaluation scope of each level was obtained quantitatively and intuitively. The risk assessment of karst tunnels was realized. Francesca et al. [18] established a floating risk evaluation model for shield construction tunnel slices based on the cloud model and evidence theory, and provided corresponding treatment measures for materials with low safety grades. The new idea and method were provided for floating risk evaluation and management of tunnel slices in the construction stage. Wu Quanli et al. [19] used the network analysis method to build a risk evaluation model of shield construction, and analyzed the weight sorting of different levels of risk control technology under the condition of multi-level risk sources. Chen Xiaoguo et al. [20] used medium wisdom set, entropy method and weighted integrated operator to establish the TBM construction disaster risk warning model of long inclined well coal mines. They also established four hierarchical classification standards of general risk, significant risk, high risk, and extreme risk, and analyzed the tunnel boring machine (TBM) construction risk of the relevant long inclined coal mine of Shenhua Group. Chen Sanqiang et al. [21] combined the Copula function with the cloud model and proposed a model for operating tunnel leakage hazard rating evaluation. They established the first level in five aspects: natural conditions, surrounding rock and groundwater, tunnel design, construction, and operation. They proposed 17 specific secondary sub-factors and obtained the evaluation system and grading evaluation standard of the water leakage hazard index of the subway tunnel operation. There are some problems of uncertain monitoring information in the surrounding rock safety evaluation index system of the mountain tunnel, so it is difficult to express it with specific values or fuzzy numbers. The vague set can describe delicately and accurately uncertain information, which has been widely used in risk assessment, investment decisions, and supplier selection in recent years [22-25]. The vague set added non-membership feature functions to the fuzzy set, which could represent the approval, opposition, and abstention in the evaluation information simultaneously, and could also partly reflect the evaluation bias generated by the evaluator based on the net preference perspective and empirical analysis. Using the similarity function could classify the vague number, the existing similarity functions were generally defective in the unreasonable classification, which is mainly due to the inadequate consideration of the hesitation degree in the uncertain information. Therefore, it is necessary to propose a reasonable and effective similarity function to solve the classification problem of vague numbers.

Although the above literature has obtained rich research results, there are still some deficiencies. First, there is no perfect index system for the tunnel surrounding rock classification. Second, the index system is mostly static and the weight determination is excessively subjective. Third, the selections of index values are mostly real numbers, which are often fuzzy in actual engineering. Based on this, a new evaluation index system is constructed from the perspective of engineering geological structure and dynamic properties of the rock body, and the range of values of different grades are proposed in this paper. Index weights were obtained with the subjective and objective comprehensive right confirmation method, and the hierarchical dynamic evaluation model of tunnel surrounding rock was established with the help of the vague set theory. Finally, the safety evaluation of Xieyuan Tunnel is analyzed. 
The rest of the study is organized as follows. In Section 3 , the basic concepts of vague sets are introduced, several common similarity functions are reviewed, a new vague similarity function are proposed, a safety evaluation index system for surrounding rock of mountain tunnels is established, and a safety evaluation method is proposed based on the vague set. In Section 4, the Xieyuan Tunnel project is used as an example to illustrate the feasibility and effectiveness of this method. In Section 5, the conclusion of this study is summarized.

\section{Methodology}

\subsection{Basic theory}

The vague set is an extension of the traditional fuzzy set. It divides the membership degree into two aspects of support and opposition for unified analysis. Thus, the vague set can express the fuzzy information of things comprehensively. The basic concepts are briefly introduced below.

Definition 1: [26] Let $U$ be a universe of discourse, any element of which is represented by $x$, a vague set $A$ on $U$ is described by the true membership function $t_{A}$ and the false membership function $f_{A}$. There are $t_{A}: U \rightarrow[0,1], f_{A}: U \rightarrow[0,1]$, if $x \in U$. Then $t_{A}(x)$ is the positive membership degree derived from the evidence supporting $x \in A, f_{A}(x)$ is the negative membership degree derived from the evidence against $x \in A$, and $t_{A}(x)+f_{A}(x) \leq 1 .\left[t_{A}(x), 1-f_{A}(x)\right]$ is a vague value of the element $x$ in vague set $A$, abbreviated as $x=\left[t_{A}(x), 1-f_{A}(x)\right]$, and $\pi_{A}(x)=1-t_{A}(x)-f_{A}(x)$ is the hesitation degree of $x$ to $A$, which is also known as the degree of unknown.

Definition 2: [26] Let $A$ and $B$ be the two vague sets in the domain U. $A$ is included in $B$, if and only if $x \in U$, $t_{A}(x) \leq t_{B}(x), f_{A}(x) \geq f_{B}(x)$, which is written as $A \subseteq B$.

Definition 3: [26] Let $A$ and $B$ be the two vague sets in the domain U. $A$ is equal to $B$, if and only if $x \in U$, $t_{A}(x)=t_{B}(x), 1-f_{A}(x)=1-f_{B}(x)$, which is written as $A=B$.

\subsection{Similarity function}

\subsubsection{Insufficiency of the existing similarity function}

Let $x=\left[t_{x}, 1-f_{x}\right]$ and $y=\left[t_{y}, 1-f_{y}\right]$ be the two vague sets in the domain $\mathrm{U}$, the similarity function formula given in [26-28] are as follows.

(1) The similarity measure defined by Chen [27] is $s_{C}(x, y)=1-\frac{\left|\left(t_{x}-t_{y}\right)-\left(f_{x}-f_{y}\right)\right|}{2}$

(2) The similarity measure defined by Hong [28] is $s_{H}=1-\frac{\left|t_{x}-t_{y}\right|+\left|f_{x}-f_{y}\right|}{2}$

(3) The similarity measure defined by Li Fan [26] is $s_{L}=1-\left[\frac{\left|\left(t_{x}-t_{y}\right)-\left(f_{x}-f_{y}\right)\right|}{4}+\frac{\left|t_{x}-t_{y}\right|+\left|f_{x}-f_{y}\right|}{4}\right]$

Although the similarity function given above can sort things by similarity, it does not fully reflect the influence of the distance between the true membership and the false membership on the similarity. The second calculation of distance also determines the degree of discrimination of similarity. Based on this, we provided a new and improved similarity function formula for multi-criteria evaluation and ranking.

Although the similarity function provided above can be sorted for the similarity between things, it does not fully reflect the effect of the distance between the true membership and the false membership on the similarity. The quadratic operation of the distance also determines the discrimination size of the similarity. Thus, a new and improved similarity function formula is used for multicriteria evaluation and ranking.

\subsubsection{New similarity function}

Definition 4: Let $x=\left[t_{x}, 1-f_{x}\right]$ and $y=\left[t_{y}, 1-f_{y}\right]$ be the two vague values in the domain $X$, if

$s(x, y)=1-\frac{\sqrt{\left|t_{x}-t_{y}\right|}+\sqrt{\left|f_{x}-f_{y}\right|}}{2}$

Then, $s(x, y)$ is called the similarity measure function of the two vague values $x$ and $y$.

\subsubsection{Comparison and analysis of the similarity of the new vague value}

To analyze the advantages of the similarity function $s(x, y)$ in Definition 4, it is compared with the similarity in the related literature and analyzed as follows.

To reflect the similar validity of the definition in this study, three sets of data are listed in Table 1.

Table. 1. Comparison of three sets of vague value data and four similarity measures

\begin{tabular}{c|c|c|c}
\hline $\begin{array}{c}\text { vague value and } \\
\text { similarity }\end{array}$ & $\begin{array}{c}\text { The first } \\
\text { group }\end{array}$ & $\begin{array}{c}\text { The second } \\
\text { group }\end{array}$ & $\begin{array}{c}\text { The third } \\
\text { group }\end{array}$ \\
\hline$x$ & {$[0,1]$} & {$[0.1,0.3]$} & {$[0.1,0.3]$} \\
$y$ & {$[0.5,0.5]$} & {$[0.4,1]$} & {$[0.5,0.9]$} \\
$s_{C}$ & 1 & 0.5 & 0.5 \\
$s_{L}$ & 0.75 & 0.5 & 0.5 \\
$s_{H}$ & 0.5 & 0.5 & 0.5 \\
$s$ & 0.293 & 0.307 & 0.296 \\
\hline
\end{tabular}

(1) For the first set of data, because $x \neq y$, there will be $s_{C}=1$ according to the similarity measure defined by Chen [27]. Obviously, this result does not comply with the definition of similarity.

(2) For the second and the third sets of data, if it is calculated according to the similarity measure defined by Chen [27], Hong [28] and Li Fan [26], there will be $d_{C}=d_{L}=d_{H}=0.5$. Obviously, the distinction degree of the three similarities is insufficient.

(3) For the similarity measure proposed in this paper, the calculated values of the similarities of $[0.1,0.3],[0.4,1]$, and $[0.5,0.9]$ are unequal. The similarity measure provided in this paper can measure the difference between them.

\subsection{A novel safety evaluation method for the tunnel} surrounding rock based on vague set

\subsubsection{Problem description}

Let $V=\left\{V_{1}, V_{2}, V_{3}, V_{4}\right\}$ be the classification factor sets of the tunnel surrounding rock. There are four sets, such as 
$V_{1}=\left\{v_{11}, v_{12}, v_{13}, v_{14}, v_{15}\right\} \quad, \quad V_{2}=\left\{v_{21}, v_{22}\right\} \quad, \quad V_{3}=\left\{v_{31}, v_{32}\right\} \quad$, $V_{4}=\left\{v_{41}, v_{42}, v_{43}\right\}$, in which $V_{1}$ denotes the physical properties of rocks; $V_{2}$ denotes the integrity of the rock mass; $V_{3}$ denotes the joint state; $V_{4}$ denotes the geological structure and groundwater influence. $v_{11}$ denotes the rock abrasion resistance; $v_{12}$ denotes the rock hardness; $v_{13}$ denotes the uniaxial compressive strength; $v_{14}$ denotes the rock cohesion; $v_{15}$ denotes the elastic longitudinal wave velocity of surrounding rock. $v_{21}$ denotes the characteristic parameters of rock mass discontinuities; $v_{22}$ denotes the rock mass integrity factor. $v_{31}$ denotes the joint spacing; $v_{32}$ denotes the joint development degree. $v_{41}$ denotes the angle between the structural plane and the tunnel axis; $v_{42}$ denotes the unit water inflow; and $v_{43}$ denotes the tunnel dryness.

The hierarchical set of tunnel surrounding rock $U=\left\{U_{1}, U_{2}, U_{3}, U_{4}, U_{5}\right\}$, among which $U_{1}$ denotes Level I; $U_{2}$ denotes Level II; $U_{3}$ denotes Level III; $U_{4}$ denotes Level IV; $U_{5}$ denotes Level V.

Benefit type:
$t_{A}(x)=\left\{\begin{array}{cc}1 & \left(x \geq x_{\max }\right) \\ \frac{x-x_{\min }}{x_{\max }-x_{\min }} & \left(x_{\min } \leq x \leq x_{\max }\right) ; \\ 0 & \left(x \leq x_{\min }\right)\end{array}\right.$

Cost type:

$t_{A}(x)=\left\{\begin{array}{cc}1 & \left(x \leq x_{\text {min }}\right) \\ \frac{x_{\text {max }}-x}{x_{\text {max }}-x_{\text {min }}} & \left(x_{\text {min }} \leq x \leq x_{\text {max }}\right) \\ 0 & \left(x \geq x_{\text {max }}\right)\end{array}\right.$

The vague value of the indicator is recorded as $\left[t_{A}\left(x_{i}\right), 1-f_{A}\left(x_{i}\right)\right]$, among which $1-f_{A}\left(x_{i}\right)-t_{A}\left(x_{i}\right)$ is the standardized interval length.

In relative risk level, there are some cost type indexes, such as $v_{11}, v_{12}, v_{13}, v_{14}, v_{15}, v_{21}, v_{22}, v_{31}, v_{32}, v_{41}, v_{43}$. The benefit type index is $v_{42}$. The indicators belong to different levels, which are shown in Table 2. $v_{12}, v_{32}$, and $v_{43}$ are assigned respectively according to $[0,0.2],[0.2,0.4],[0.4,0.6]$, $[0.6,0.8]$, and $[0.8,1]$. The ranges of each indicator value are $0 \leq v_{11} \leq 9,0 \leq v_{13} \leq 250,0 \leq v_{14} \leq 0.25,0 \leq v_{15} \leq 5,0 \leq v_{21} \leq 10$, $0 \leq v_{42} \leq 30,0 \leq v_{31} \leq 2.5,0 \leq v_{41} \leq 90$, and $0 \leq v_{42} \leq 150$. The vague values of each index relative to different surrounding rock grades are calculated according to formula (2) and (3), as shown in Table 3.

Table 2. Value range of each index relative to the safety level of the surrounding rock of the tunnel

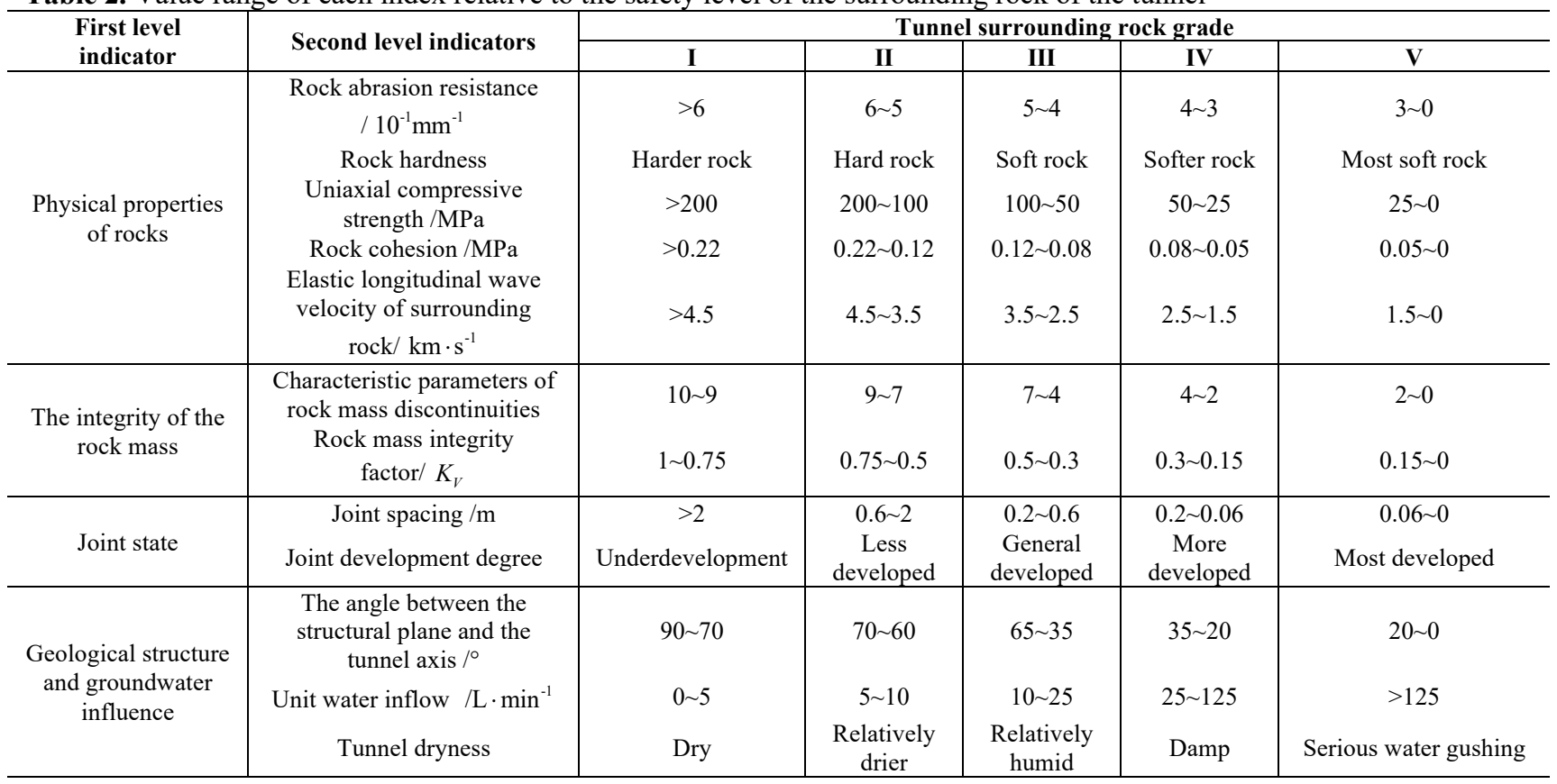

Table 3. Subordination interval of each index relative to the safety grade of the surrounding rock of Tunnel

\begin{tabular}{|c|c|c|c|c|c|c|}
\hline \multirow{2}{*}{ First level indicator } & \multirow{2}{*}{ Second level indicators } & \multicolumn{5}{|c|}{ Tunnel surrounding rock grade } \\
\hline & & $\mathbf{I}$ & II & III & IV & $\mathbf{V}$ \\
\hline \multirow{5}{*}{$\begin{array}{l}\text { Physical properties of } \\
\text { rocks }\end{array}$} & $\begin{array}{c}\text { Rock abrasion resistance } \\
\qquad / 10^{-1} \mathrm{~mm}^{-1}\end{array}$ & {$[0,0.33]$} & {$[0.33,0.44]$} & {$[0.44,0.56]$} & {$[0.56,0.67]$} & {$[0.67,1]$} \\
\hline & Rock hardness & {$[0,0.20]$} & {$[0.20,0.40]$} & {$[0.40,0.60]$} & {$[0.60 .0 .80]$} & {$[0.80,1]$} \\
\hline & $\begin{array}{c}\text { Uniaxial compressive } \\
\text { strength } / \mathrm{MPa}\end{array}$ & {$[0,0.20]$} & {$[0.20,0.60]$} & {$[0.60,0.80]$} & {$[0.80,0.90]$} & {$[0.90,1]$} \\
\hline & Rock cohesion / $\mathrm{MPa}$ & {$[0,0.12]$} & {$[0.12,0.52]$} & {$[0.52,0.68]$} & {$[0.68,0.80]$} & {$[0.80,1]$} \\
\hline & $\begin{array}{c}\text { Elastic longitudinal wave } \\
\text { velocity of surrounding rock } \\
\qquad / \mathrm{km} \cdot \mathrm{s}^{-1}\end{array}$ & {$[0,0.10]$} & {$[0.10,0.30]$} & {$[0.30,0.50]$} & {$[0.50,0.70]$} & {$[0.70,1]$} \\
\hline $\begin{array}{c}\text { The integrity of the rock } \\
\text { mass }\end{array}$ & $\begin{array}{l}\text { Characteristic parameters of } \\
\text { rock mass discontinuities }\end{array}$ & {$[0,0.10]$} & {$[0.10,0.30]$} & {$[0.30,0.60]$} & {$[0.60,0.80]$} & {$[0.80,1]$} \\
\hline
\end{tabular}




\begin{tabular}{|c|c|c|c|c|c|c|}
\hline & $\begin{array}{l}\text { Rock mass integrity factor } \\
\qquad / K_{V}\end{array}$ & {$[0,0.25]$} & {$[0.25,0.50]$} & {$[0.50,0.70]$} & {$[0.70,0.85]$} & {$[0.85,1]$} \\
\hline Joint state & $\begin{array}{c}\text { Joint spacing /m } \\
\text { Joint development degree }\end{array}$ & $\begin{array}{l}{[0,0.25]} \\
{[0,0.20]}\end{array}$ & $\begin{array}{l}{[0.25,0.76]} \\
{[0.20,0.40]}\end{array}$ & $\begin{array}{l}{[0.76,0.92]} \\
{[0.40,0.60]}\end{array}$ & $\begin{array}{l}{[0.92,0.98]} \\
{[0.60,0.80]}\end{array}$ & $\begin{array}{l}0.98,1] \\
{[0.80,1]}\end{array}$ \\
\hline $\begin{array}{l}\text { Geological structure and } \\
\text { groundwater influence }\end{array}$ & $\begin{array}{l}\text { The angle between the } \\
\text { structural plane and the } \\
\text { tunnel axis } /{ }^{\circ} \\
\text { Unit water inflow } / \mathrm{L} \cdot \mathrm{min}^{-1} \\
\text { Tunnel dryness }\end{array}$ & $\begin{array}{l}{[0,0.22]} \\
{[0,0.03]} \\
{[0,0.20]}\end{array}$ & $\begin{array}{l}{[0.22,0.33]} \\
{[0.03,0.07]} \\
{[0.20,0.40]}\end{array}$ & $\begin{array}{l}{[0.33,0.61]} \\
{[0.07,0.17]} \\
{[0.40,0.60]}\end{array}$ & $\begin{array}{l}{[0.61,0.78]} \\
{[0.17,0.83]} \\
{[0.60,0.80]}\end{array}$ & $\begin{array}{l}{[0.78,1]} \\
{[0.83,1]} \\
{[0.80,1]}\end{array}$ \\
\hline
\end{tabular}

\subsubsection{Determination of the weight of safety evaluation} index

(1) Determination of subjective weight

A method is presented to calculate the weight vector $W=\left(w_{1}, w_{2}, \cdots, w_{n}\right)^{T}$

It is known from the property that the corresponding matrix is $A^{*}=\left(\frac{w_{i}}{w_{j}}\right)_{n \times n}=\left(a_{i j}^{*}\right)_{n \times n}$, in which $w_{i}=\frac{1}{n} \sum_{j=l}^{n} \frac{a_{i j}^{*}}{\sum_{k=l}^{n} a_{k j}^{*}}, i=1,2, \cdots, n$. Let $w_{i}=\frac{1}{n} \sum_{j=l}^{n} \frac{a_{i j}^{*}}{\sum_{k=l}^{n} a_{k j}^{*}}, i=1,2, \cdots, n$ be suited for a given judgment matrix $A=\left(a_{i j}\right)_{n \times n}$.
$W=\left(w_{1}, w_{2}, \cdots, w_{n}\right)^{T}$ is the weight vector. Because there is $\sum_{j=1}^{n} a_{i j} w_{j}=\lambda_{i} w_{i},(i=1,2, \cdots, n), \quad \lambda_{\max }=\frac{1}{n} \sum_{i=1}^{n} \frac{\sum_{j=1}^{n} a_{i j} w_{j}}{w_{i}}$ can be obtained.

The corresponding characteristic root $\lambda_{\max }$ is calculated according to the judgment matrix $A$, where $W$ is the weight of the evaluation factor. The consistency index is $C I=\left(\lambda_{\max }-n\right) /(n-1)$, where $\mathrm{n}$ is the order of the matrix. A consistency check is conducted with $C R=C I / R I$.

If $C R<0.10$, we believe that the judgment matrix $A$ passed the consistency test; If $C R \geq 0.10$, we believe that the judgment matrix $A$ has failed the consistency test. The value of the judgment matrix needs to be redetermined before performing a consistency test.

The values of $R I$ are shown in Table 4 .

Table.4. Mean Random Consistency Index value

\begin{tabular}{c|c|c|c|c|c|c|c|c|c|c|c|c|c|}
\hline Order $\mathrm{n}$ & 1 & 2 & 3 & 4 & 5 & 6 & 7 & 8 & 9 & 10 & 11 \\
\hline RI value & 0 & 0 & 0.58 & 0.90 & 1.12 & 1.24 & 1.32 & 1.41 & 1.45 & 1.49 & 1.51 \\
\hline
\end{tabular}

(2) Objective weight determination

Let the domain be $X=\left\{x_{1}, x_{2}, \cdots, x_{n}\right\}$, while the vague set is $A=\left\{\left[t_{A}\left(x_{i}\right), 1-f_{A}\left(x_{i}\right)\right] \mid x_{i} \in X\right\}$, then we call the entropy of vague sets as

$$
E(A)=\frac{1}{n} \sum_{i=1}^{n}\left\{1-\frac{1}{\sqrt{2}} \sqrt{t_{A}^{2}\left(x_{i}\right)+f_{A}^{2}\left(x_{i}\right)+\left(1-\pi_{A}\left(x_{i}\right)\right)^{2}}\right\}
$$

The weight determined according to the principle of large entropy and small weight is

$$
w_{i}=\frac{1-E\left(A_{i}\right)}{\sum_{i=1}^{n}\left(1-E\left(A_{i}\right)\right)}
$$

(3) Optimization of subjective and objective weights

The weight vector of each indicator obtained by subjective weighting is $\omega^{L}=\left(\omega_{1}^{L}, \omega_{2}^{L}, \cdots, \omega_{12}^{L}\right)$. The one obtained by objective weighting is $\omega^{U}=\left(\omega_{1}^{U}, \omega_{2}^{U}, \cdots, \omega_{12}^{U}\right)$. The index interval weight obtained by general analysis of the subjective and objective empowerment is $\omega=\left(\omega_{1}, \omega_{2}, \cdots \omega_{12}\right)$, among which $\omega_{i}=\left(\omega_{i}^{-}, \omega_{i}^{+}\right), \quad \omega_{i}^{-}=\min \left\{\omega_{i}^{L}, \omega_{i}^{U}\right\} \quad$, $\omega_{i}^{+}=\max \left\{\omega_{j}^{L}, \omega_{j}^{U}\right\}, i, j=1,2, \cdots, 12$. To improve the distinction of the tunnel surrounding rock evaluation level, the weight is optimized according to the absolute value maximization principle of membership and non-membership difference. Let the vague value of the tunnel surrounding rock grade be $\left[T_{j}, 1-F_{j}\right]$, in which $T_{j}=\sum_{i=1}^{12} \omega_{i} t_{i j}, 1-F_{j}=\sum_{i=1}^{5} \omega_{i}\left(1-f_{i j}\right)$.

$$
\max \sum_{j=1}^{5}\left|T_{j}-F_{j}\right|=\max \left(\sum_{j=1}^{5} \sum_{i=1}^{12} \omega_{i}\left|t_{i j}-f_{i j}\right|\right)
$$

S.T. $\omega_{i}^{-} \leq \omega_{i} \leq \omega_{i}^{+}, i=1,2, \cdots, 12$

$\sum_{i=1}^{12} \omega_{i}=1$

The final weight calculated by programming with the Matlab7.0 software is $W=\left(\omega_{1}, \omega_{2}, \cdots \omega_{12}\right)$.

\subsubsection{Safety evaluation process of tunnel surrounding rock based on vague set}

For some unevaluated tunnel surrounding rocks, the specific evaluation steps are as follows:

(1) To determine Each index data of the evaluated tunnel surrounding rock and convert it into the vague value. To obtain the evaluation matrix $R=\left(r_{i j}\right)_{m \times n}$ of the unevaluated tunnel surrounding rocks , among which $r_{i j}$ $(1 \leq i \leq m, 1 \leq j \leq n)$ is the vague value of the $i$ index factor on the $j$ level in the evaluation objects.

(2) To process all the data by using the method of Definition 4 and find the similarity matrix $s_{k}=\left(s_{i j}\right)_{m \times n}$ $(1 \leq k \leq 4)$ of each secondary index for different security levels.

(3) To determine the individual index weight $W$ by using the subjective and objective weight optimization method.

(4) To synthesize each second-level similarity matrix $s_{k}=\left(s_{i j}\right)_{m \times n}$ by using the weighted sum method formula 
$s_{i j}^{*}=\sum_{j=1}^{n_{1}} w_{i j} s_{i j}$ to obtain the first-level similarity matrix $s^{*}=\left(s_{i j}^{*}\right)_{m \times n}$.

(5) To assemble the comprehensive evaluation matrix for each level similarity matrix by using the weighted sum method formula $s_{j}=\sum_{i=1}^{4} w_{i} s_{i j}^{*}$. Determine the safety level of the evaluated tunnel surrounding rock according to the maximum similarity principle belonging to different grades.

\section{Result Analysis and Discussion}

\subsection{Case study}

Xieyuan Tunnel is located in the Nanping section of the Haixi Expressway Network in Fujian Province, China, with a length of $4472 \mathrm{~m}$. The entrance of Xieyuan Tunnel is located in the mountain about $1.5 \mathrm{~km}$ southeast of Kengkou
Village in Nanshan Town, and the exit tunnel is located in the mountain about $300 \mathrm{~m}$ southwest of Qianyang Village in Yanghou Town. The entrance is only connected by field roads and the traffic conditions are relatively poor. The exit is located on the side of a county road and the traffic conditions are better. The tunnel clearance (width $\times$ height) is $10.25 \mathrm{~m} \times 5.0 \mathrm{~m}$, which is a double tunnel separated tunnel. The left tunnel is $4451 \mathrm{~m}$ long, starting and ending stakes: ZK36+692.0 ZK41+143.0, and center stakes: ZK38+917.5. The right tunnel is $4472 \mathrm{~m}$ long, starting and ending stakes: YK36+715.00 $\sim$ YK41+187.00, and center stakes: YK38+951.0. The maximum depth is about $460 \mathrm{~m}$, the inlet tunnel door is of the bamboo type, and the exit tunnel door is of the end wall type. All index values are obtained by consulting the construction materials of Xieyuan Tunnel and on-site survey, as shown in Table 5.

Table 5. Related Index Values of Xieyuan Tunnel Surrounding Rock

\begin{tabular}{|c|c|c|c|c|c|}
\hline Index & Data value & Index & Data value & Index & Data value \\
\hline $\begin{array}{l}\text { Rock abrasion } \\
\text { resistance } / 10^{-1} \mathrm{~mm}^{-1}\end{array}$ & $4.3 \sim 4.4$ & $\begin{array}{l}\text { Elastic longitudinal wave } \\
\text { velocity of surrounding } \\
\text { rock } / \mathrm{km} \cdot \mathrm{s}^{-1}\end{array}$ & $2.8 \sim 3$ & $\begin{array}{c}\text { Joint development } \\
\text { degree }\end{array}$ & More developed \\
\hline Rock hardness & Hard rock & $\begin{array}{l}\text { Characteristic parameters } \\
\text { of rock mass discontinuities }\end{array}$ & $5.5 \sim 5.8$ & $\begin{array}{l}\text { The angle between the } \\
\text { structural plane and the } \\
\text { tunnel axis } /^{\circ}\end{array}$ & $75 \sim 78$ \\
\hline $\begin{array}{l}\text { Uniaxial compressive } \\
\text { strength } / \mathrm{MPa}\end{array}$ & $48 \sim 53$ & $\begin{array}{l}\text { Rock mass integrity factor } \\
\qquad / K_{V}\end{array}$ & $0.6 \sim 0.65$ & $\begin{array}{l}\text { Unit water inflow } \\
\qquad / \mathrm{L} \cdot \mathrm{min}^{-1}\end{array}$ & $50 \sim 65$ \\
\hline Rock cohesion /MPa & $0.18 \sim 0.2$ & Joint spacing $/ \mathrm{m}$ & $0.4 \sim 0.5$ & Tunnel dryness & Damp \\
\hline
\end{tabular}

\subsection{Result analysis}

(1) Each index data of the surrounding rock of the tunnel is determined to be evaluated and is converted into the vague value. The evaluation matrix $R=\left(r_{i j}\right)_{m \times n}$ of the surrounding rock is obtained, where $r_{i j}$ is the vague value of the index factor " $\mathrm{i}$ " on the level " $\mathrm{j}$ " in the object to be evaluated, where $1 \leq i \leq m, 1 \leq j \leq n$.

The vague values of each index are calculated with the data in Table 5 by formulas (2) and (3), as shown in Table 6.

Table 6. Vague value of Xieyuan tunnel surrounding rock index

\begin{tabular}{c|c|c|c|c|c}
\hline index & vague value & index & vague value & index & vague value \\
\hline $\begin{array}{c}\text { Rock abrasion } \\
\text { resistance/ } 10^{-1} \mathrm{~mm}^{-1}\end{array}$ & {$[0.51,0.52]$} & $\begin{array}{c}\text { Elastic longitudinal } \\
\text { wave velocity of } \\
\text { surrounding } \\
\text { rock/ } \mathrm{km} \cdot \mathrm{s}^{-1} \\
\text { Characteristic } \\
\text { parameters of rock } \\
\text { mass discontinuities } \\
\text { Rock mass integrity } \\
\text { factor } K_{V}\end{array}$ & {$[0.4,0.44]$} & $\begin{array}{c}\text { Joint development } \\
\text { degree }\end{array}$ & {$[0.6,0.8]$} \\
$\begin{array}{c}\text { Uniaxial compressive } \\
\text { strength/MPa }\end{array}$ & {$[0.2,0.4]$} & {$[0.42,0.45]$} & $\begin{array}{c}\text { The angle between the } \\
\text { structural plane and the } \\
\text { tunnel axis/ } \\
\text { Unit water } \\
\text { Rock cohesion/MPa }\end{array}$ & $\begin{array}{c}\text { Unflow } / \mathrm{L} \cdot \mathrm{min}^{-1} \\
\text { Tunnel dryness }\end{array}$ & {$[0.13,0.17]$} \\
\hline
\end{tabular}

(2) All data in $R$ are processed by using equation (1), and the similarity matrix $s_{k}=\left(s_{i j}\right)_{m \times n}$ of each secondary security index for different safety levels is found. All similarity values are shown in Table 7 .

Table 7. Similarity value of the secondary indicators relative to different security levels

\begin{tabular}{|c|c|c|c|c|c|c|}
\hline \multirow{2}{*}{ First level indicator } & \multirow{2}{*}{ Secondary indicators } & \multicolumn{5}{|c|}{ Tunnel surrounding rock grade } \\
\hline & & $\mathbf{I}$ & II & III & IV & $\mathbf{V}$ \\
\hline \multirow{5}{*}{$\begin{array}{l}\text { Physical properties of } \\
\text { rocks }\end{array}$} & $\begin{array}{c}\text { Rock abrasion } \\
\text { resistance } / 10^{-1} \mathrm{~mm}^{-1}\end{array}$ & 0.4250 & 0.6464 & 0.7677 & 0.6945 & 0.4536 \\
\hline & Rock hardness & 0.5528 & 1.0000 & 0.5528 & 0.3675 & 0.2254 \\
\hline & $\begin{array}{c}\text { Uniaxial compressive } \\
\text { strength/MPa }\end{array}$ & 0.1651 & 0.3868 & 0.7321 & 0.8000 & 0.6162 \\
\hline & Rock cohesion/MPa & 0.5764 & 0.6136 & 0.4009 & 0.2930 & 0.1884 \\
\hline & $\begin{array}{l}\text { Elastic longitudinal wave } \\
\text { velocity of surrounding } \\
\text { rock } / \mathrm{km} \cdot \mathrm{s}^{-1}\end{array}$ & 0.3922 & 0.5391 & 0.7194 & 0.5869 & 0.3520 \\
\hline Integrity of rock mass & Characteristic parameters of rock & 0.3802 & 0.5235 & 0.6331 & 0.4921 & 0.3210 \\
\hline
\end{tabular}




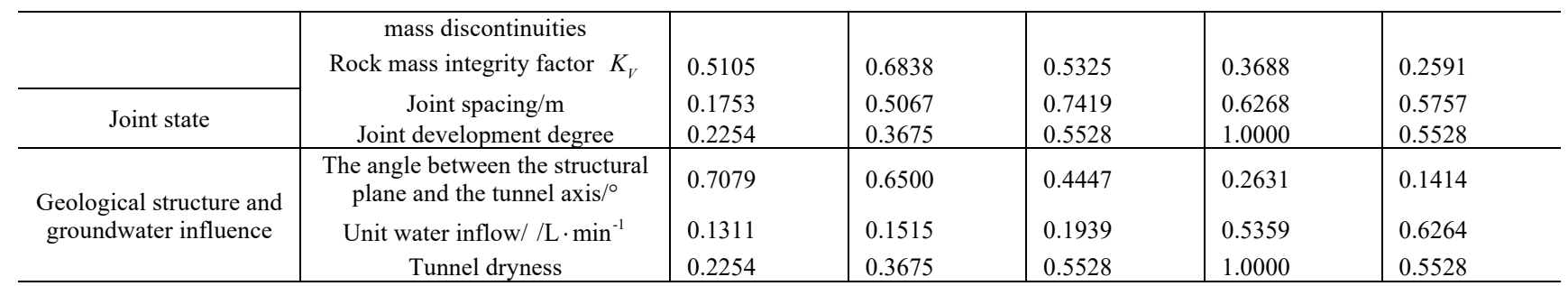

Similarity matrix is $s=\left(s_{1} ; s_{2} ; s_{3} ; s_{4}\right)$.

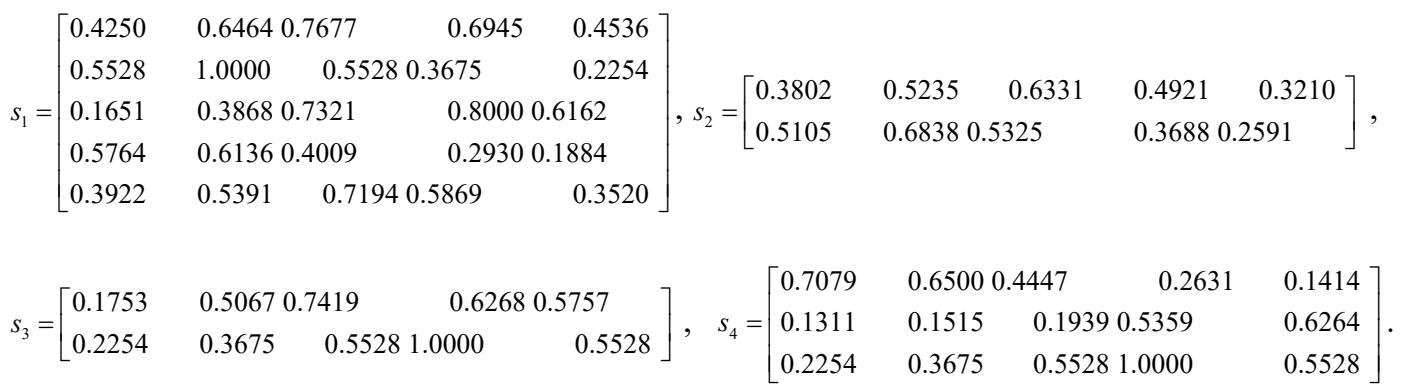

(3) Each index weight $W$ is determined by using the subjective and objective weight optimization method.
The weights of all indicators are calculated and the results are shown in Table 8 .

Table 8. Summary table of index weights

\begin{tabular}{|c|c|c|c|c|c|c|}
\hline $\begin{array}{l}\text { First level } \\
\text { indicator }\end{array}$ & $\begin{array}{l}\text { The weight of the } \\
\text { first-level index } \\
\text { level analysis }\end{array}$ & Secondary indicators & $\begin{array}{c}\text { The weight of } \\
\text { secondary index } \\
\text { hierarchical analysis } \\
\end{array}$ & $\begin{array}{l}\text { Entropy } \\
\text { weight }\end{array}$ & $\begin{array}{c}\text { AHP } \\
\text { weight }\end{array}$ & $\begin{array}{l}\text { Weight after } \\
\text { optimization }\end{array}$ \\
\hline $\begin{array}{l}\text { Physical } \\
\text { properties of } \\
\text { rocks }\end{array}$ & 0.3916 & $\begin{array}{c}\text { Rock abrasion } \\
\text { resistance/ } 10^{-1} \mathrm{~mm}^{-1} \\
\text { Rock hardness } \\
\text { Uniaxial compressive } \\
\text { strength } / \mathrm{MPa} \\
\text { Rock cohesion } / \mathrm{MPa} \\
\text { Elastic longitudinal wave } \\
\text { velocity of surrounding } \\
\text { rock } / \mathrm{km} \cdot \mathrm{s}^{-1}\end{array}$ & $\begin{array}{l}0.1757 \\
0.1149 \\
0.3686 \\
0.2563 \\
0.0845\end{array}$ & $\begin{array}{l}0.0965 \\
0.0781 \\
0.0849 \\
0.0787 \\
0.0763\end{array}$ & $\begin{array}{l}0.0671 \\
0.0463 \\
0.1502 \\
0.0900 \\
0.0367\end{array}$ & $\begin{array}{l}0.0965 \\
0.0781 \\
0.0849 \\
0.0787 \\
0.0751\end{array}$ \\
\hline $\begin{array}{l}\text { Integrity of rock } \\
\text { mass }\end{array}$ & 0.1942 & $\begin{array}{l}\text { Characteristic parameters of } \\
\text { rock mass discontinuities } \\
\text { Rock mass integrity factor } K_{V}\end{array}$ & $\begin{array}{l}0.2800 \\
0.7200\end{array}$ & $\begin{array}{l}0.0774 \\
0.0843\end{array}$ & $\begin{array}{l}0.0489 \\
0.1466\end{array}$ & $\begin{array}{l}0.0489 \\
0.1458\end{array}$ \\
\hline Joint state & 0.1379 & $\begin{array}{c}\text { Joint spacing/m } \\
\text { Joint development degree }\end{array}$ & $\begin{array}{l}0.1659 \\
0.8341 \\
\end{array}$ & $\begin{array}{l}0.0961 \\
0.0778 \\
\end{array}$ & $\begin{array}{l}0.0221 \\
0.1161 \\
\end{array}$ & $\begin{array}{l}0.0221 \\
0.1161 \\
\end{array}$ \\
\hline $\begin{array}{l}\text { Geological } \\
\text { structure and } \\
\text { groundwater } \\
\text { influence }\end{array}$ & 0.2763 & $\begin{array}{c}\text { The angle between the } \\
\text { structural plane and the tunnel } \\
\text { axis } /{ }^{\circ} \\
\text { Unit water inflow } / \mathrm{L} \cdot \mathrm{min}^{-1} \\
\text { Tunnel dryness }\end{array}$ & $\begin{array}{l}0.3103 \\
0.4935 \\
0.1962\end{array}$ & $\begin{array}{l}0.0814 \\
0.0793 \\
0.0891\end{array}$ & $\begin{array}{l}0.0877 \\
0.1363 \\
0.0521\end{array}$ & $\begin{array}{l}0.0877 \\
0.0793 \\
0.0891\end{array}$ \\
\hline
\end{tabular}

(4) Each second-level similarity matrix $s_{k}=\left(s_{i j}\right)_{m \times n}$ is synthesized by using the weighted sum method formula $s_{i j}^{*}=\sum_{j=1}^{n_{1}} w_{i j} s_{i j}$ to obtain the first-level similarity matrix $s^{*}=\left(s_{i j}^{*}\right)_{m \times n}$.

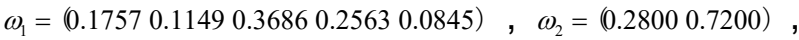

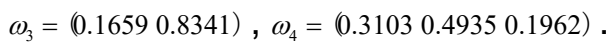

$s^{*}=\left[\begin{array}{lllll}0.3799 & 0.5737 & 0.6318 & 0.5838 & 0.4108 \\ 0.4740 & 0.6389 & 0.5607 & 0.4033 & 0.2764 \\ 0.2171 & 0.3906 & 0.5842 & 0.9381 & 0.5566 \\ 0.3286 & 0.3486 & 0.3421 & 0.5423 & 0.4615\end{array}\right]$

(5) The comprehensive evaluation matrix $s=(0.3615,0.4989,0.5314,0.5861,0.4188)$ is assemble for each level similarity matrix by using the weighted sum method formula $s_{j}=\sum_{i=1}^{4} w_{i} s_{i j}^{*}$. According to the principle of maximum similarity, Xieyuan Tunnel in Fujian is determined to belong to Class IV.

\section{Conclusions}

There is uncertainty in the safety evaluation of mountain tunnel, which reduces the reliability of the evaluation results. To characterize and process the evaluation information of uncertainty, the safety evaluation method of mountain tunnels is proposed based on the vague set in this paper. The feasibility and effectiveness of the method are verified by an application example of the safety evaluation of Xieyuan 
Tunnel in Fujian. The research conclusions obtained in this paper are as follows:

(1) The tunnel surrounding rock safety evaluation index system, including the rock mass properties and geological structure, is constructed. The vague value of the index is given by considering the ambiguity of the engineering data. Comprehensive weight optimization is conducted according to the absolute value maximization principle of membership and non-membership difference. It improves the distinction of the surrounding rock safety evaluation results.

(2) The surrounding rock safety assessment is conducted according to the improved similarity function, and the results obtained are consistent with the actual construction safety situation, which provides a feasible and effective evaluation method for mountain tunnel engineering managers.

(3) From the data in Table 7, the secondary indicators of uniaxial compressive strength, joint development, unit water inflow, and tunnel dryness are more dangerous. It is suggested that the project security inspection personnel should monitor the four indicators in real time and make corresponding protection plans to prevent the occurrence of secondary disasters around the tunnel rock.

Compared with the conventional methods, the vague value description evaluation information is comprehensive. It will be reasonable to establish subjective and objective rights using the similarity function, which can provide higher discrimination for hierarchical recognition. The method provides the theoretical basis for tunnel surrounding rock safety evaluation for road traffic managers. However, with the continuous research problems, the evaluation index value may also be the interval value, the language value, or even the mixed occurrence or the missing information. Solving these problems is worth looking into.
In this study, a novel discrete PSO algorithm has been proposed for complex network clustering. The proposed algorithm maximizes a widely used index called modularity. In the algorithm, the particle position update rule has been redesigned so that a position label is updated with the neighbor label that generates the largest increase in modularity. The newly defined rule drives the particles to a more promising region. A novel turbulence operation is suggested for improving the exploration of the algorithm. This operation makes full use of the network linkage relationships to direct the search process. A local search strategy is developed to enhance the exploitation of the algorithm. The local search procedure is carried out on the leader particle. To validate the performance of the proposed algorithm, extensive experiments have been performed on both synthetic and real-world networks. We have compared the proposed algorithm with three state-of-the-art methods. All the experiments demonstrate that the proposed algorithm is effective and promising.

\section{Acknowledgements}

This work was supported by the Scientific Research Start-up fund of the High-level Talents Introduction Project of Sanming University (19YG01, 19YG03), Natural Science Foundation of Fujian Province of China (2020J01384, 2020J01391), the Education and Scientific Research Project for Young and Middle-aged Teachers of the Fujian Province Education Department (JAT190688, B201901), and the Joint Guiding Project of the Heilongjiang Natural Science Foundation (LH2019E085).

This is an Open Access article distributed under the terms of the Creative Commons Attribution License.

\section{References}

1. Mssmer, S., Sulzbacher, G., Jedlitschka, G., "Brenner Base Tunnel Tunnelling in the immediate vicinity of existing structures on the Tulfes-Pfons contract". Geomechanik und Tunnelbau, 12(6), 2019, pp.708-715.

2. Lussu, A., Grüllich, S., Kaiser, C., "15 km TBM exploratory tunnel excavation in the construction Lot $\mathrm{H} 33$ of the Brenner Base Tunnel". Geomechanics and Tunnelling, 12(5), 2019, pp.595-603.

3. Herr, R., "Brenner Base Tunnel: Mixing Pump Caters for Firm Ground beneath Invert Segments”. Tunnel, 38(4), 2019, pp.41-43.

4. Celzo, F., Buyse, H., Welby S., "Safety evaluation of adverse events following vaccination with Havrix, Engerix-B or Twinrix during pregnancy". Vaccine, 38( 40), 2020, pp.6215-6223.

5. Cgb, D., Gse, F., "Safety evaluation of a new setup for transcranial electric stimulation during magnetic resonance imaging”. Brain Stimulation, 14(3), 2021, pp.488-497.

6. Studholme, L., Sutherland, J., Desai, T., "Evaluation of the monocyte activation test for the safety testing of meningococcal $B$ vaccine Bexsero: A collaborative study". Vaccine, 37(29), 2019, pp.37613769.

7. Li, M., Wang, H.T., Wang, D.M., "Risk assessment of gas explosion in coal mines based on fuzzy AHP and bayesian network". Process Safety and Environmental Protection, 2020, pp.135:207-218.

8. Chen, X., Yang, Y., Bian, X., "Improvement of the Method to Determine Weight Based on the Intuitionistic Fuzzy Entropy". International Journal of Hybrid Information Technology. 9(8), 2016, pp.377-386.

9. Galindo, H., Gallardo, J.M., Jiménez-Losada, A. "A real Shapley value for cooperative games with fuzzy characteristic function". Fuzzy Sets and Systems, 2020, doi: org/10.1016/j.fss.2020.04.019.
10. Hans, O.H., Kieffer, S., "Pre-excavation grouting in rock tunneling - Dealing with high groundwater pressures". Geomechanik und Tunnelbau, 12(2), 2019, pp.141-146.

11. Lu, Y., "Theoretical model of comprehensive hierarchical cloud optimization for the surrounding rock of interval-number tunnels". Science Technology and Engineering, 20(9), 2020, pp.3763-3769.

12. Zhang, F., Jiang, J., Zhao, L., "Dynamic classification of tunnel surrounding rock based on DE-BP model". Journal of Shenyang University of Technology, 43(1), 2021, pp.105-112.

13. Napoli, F.D., Luca, A.D., Caputo, F., "Mixed FE-MB methodology for the evaluation of passive safety performances of aeronautical seats". International journal of crashworthiness, 24(3-4), 2019, pp.314-325.

14. Atzl, G., Josmann, G., Fleissner, W., "Ground pressure-dependent segment opening options for cross passages on Koralm Tunnel contract KAT3-Development of support types for cross passage excavation to segment-lined tunnel". Geomechanik and Tunnelbau, 12(1), 2019, pp.33-44.

15. Flora, M., Goliasch, R., Strauss, A., "Hard rock tunnel boring machines-State of the art 2020". Geomechanik and Tunnelbau, 12(6), 2019, pp.721-729.

16. Erharter, G. H., Marcher, T., Reinhold, C., "Application of artificial neural networks for Underground construction-Chances and challenges - Insights from the BBT exploratory tunnel Ahrental Pfons". Geomechanik and Tunnelbau, 12(5), 2019, pp.472-477.

17. Kang, M. S., Park, H. J., Hwang, J. H., "Safety Evaluation of Biportal Endoscopic Lumbar Discectomy: Assessment of Cervical Epidural Pressure During Surgery”. Spine, 45(20), 2020, pp.13491356. 
18. Francesca, P. O., "Evaluation of veterinary autogenous vaccines safety by an MTT in-vitro cytotoxicity assay". Veterinaria italiana, 55(4), 2019, pp.299-305.

19. Wu, Q., Wang, M., Yin, M. "Risk analysis of shield underpass tunnel based on network analysis method". Chinese Journal of Underground Space and Engineering, 15(6), 2019, pp.1881-1888.

20. Chen, X., Huang, H., Yang, Y., “TBM construction disaster risk early warning model for long inclined shaft coal mine". Catastrophe Science, 34(3), 2019, pp.146-149.

21. Chen, S., Chen, H., Wu, X., "Water leakage risk assessment of subway operating tunnel based on Copula-cloud model". Journal of Civil Engineering and Management, 36(5), 2019, pp.90-101.

22. Yu, G., Fei W., Li D., "A compromise-typed variable weight decision method for hybrid multi-attribute decision making”. IEEE Transactions on Fuzzy Systems, 27(5), 2019, pp.861-872.

23. Wang, Y., Chen, F., Yin, X., "Study on the risk assessment of water inrush in karst tunnels based on intuitionistic fuzzy theory". Geomatics Natural Hazards and Risk,10(1), 2019, pp.1070-1083.
24. Wu, J., Sun, Q., Fujita, H., “An attitudinal consensus degree to control feedback mechanism in group decision making with different adjustment cost". Knowledge-Based Systems, 164(15), 2019, pp.265-273.

25. Chen, X., Du, H., Yang, Y., "The Interval-valued triangular fuzzy soft set and Its method of dynamic decision making". Journal of Applied Mathematics, 2014, doi: org/10.1155.132806.

26. Chen, X., Yu, G., Wu, J., "A Minimum Trust Discount Coefficient Model for Incomplete Information in Group Decision Making with Intuitionistic Fuzzy Soft Set". International Journal of Fuzzy Systems, 2020, doi: org/10.1007/s40815-020-00811-2.

27. Chen, S., "Measures of similarity between vague sets". Fuzzy Sets and Systems,(2), 1995, pp.217-223.

28. Hong, D. H., Kim, C., "A note on similarity between vague sets and between elements". Information Sciences,1(1), 1999, pp.83-96. 